stage liver disease scores. Pediatr Transplant, 17 (4), 362-368.

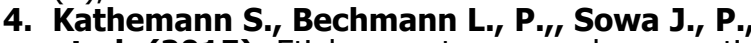
et al. (2015). Etiology, outcome, and prognostic factors of childhood acute liver failure in a German Single Center. Annals of Hepatology, 14 (5), 722-728.

5. Kulkarni S., Perez C., Pichardo C. et al. (2015). Use of Pediatric Health Information System database to study the trends in the incidence, management, etiology, and outcomes due to pediatric acute liver failure in the United States from 2008 to 2013. Pediatr Transplant, 19 (8), 888-895.

6. Lee W. S., McKierna P., Kelly D. A. (2005), Etiology, Outcome and Prognostic Indicators of Childhood Fulminant Hepatic Failure in the United Kingdom. Journal of Pediatric Gastroenterology and Nutrition, 40, 575-581.

\title{
HIỆU QUẢ DỰ PHÒNG BÊ̂NH SÂU RĂNG Ở HỌC SINH 12 TUỔI TẠI TỈNH TIỀN GIANG
}

\section{TÓM TẮT}

Đặt vấn đê: dự phòng bệnh răng miệng ở trẻ em là vấn đề ưu tiên hàng đầu nhằm giảm gánh nặng do bênh gây ra trong cộng đồng. Mục tiêu: đánh giá hiệu quả dự phòng bệnh sâu răng ở học sinh 12 tuổi tại tỉnh Tiền Giang. Phương pháp: nghiên cứu can thiệp có đối chứng, 1.259 học sinh, không sâu răng được chia thành 3 nhóm, can thiệp giáo dục sức khỏe răng miệng, súc miệng nước Fluor, trám bít hố rãnh trong 18 tháng và đánh giá kết quả sau 30 tháng. Kết quả: sau can thiệp, tỷ lệ học sinh mắc bệnh sâu răng giảm dân ở nhóm chứng, nhóm can thiệp 1 và nhóm can thiệp 2 lần lượt là 48,3\%; 17,2\% và 10,1\%. Hiệu quả can thiệp giữa nhóm can thiệp 1 và 2 so nhóm chứng trên trung bình sâu mất trám răng (SMTR) và sâu mất trám mặ̆t răng (SMTMR) tăng lần lượt là $1225 \%-1300 \%$ và $850,6 \%-856,3 \%$. Hiêu quả dư phòng bệnh sâu răng ở nhóm can thiệp 2 cao hơn nhóm can thiêp 1. Sau trám bít hố rãnh bằng Fuji VII: tỷ lệ học sinh mắc bệnh sâu răng ở nhóm can thiệp $(1,8 \%)$ thấp hơn nhóm chứng $(9,3 \%)$; hiệu quả can thiệp giữa nhóm can thiệp so nhóm chứng trên trung bình SMTR và SMTMR tăng lần lượt là $583,3 \%$ và 300\%. Kết luận: hiệu quả dự phòng bệnh sâu răng tăng cao khi phối hợp các biện pháp can thiệp. Các biện pháp dự phòng bệnh ở học sinh 12 tuổi tại tỉnh Tiền Giang đã mang lại hiệu quả cao.

Từ khóa: sâu răng, SMTR, SMTMR, Tiền Giang.

\section{SUMMARY}

\section{EFFICIENCY OF DECAY TOOTH}

\section{PREVENTION IN 12-YEAR-OLD CHILDREN} IN TIEN GIANG PROVINCE

Background: prevention of oral diseases in children is the priority issue to reduce the burden

\footnotetext{
*Bệnh viện Đa khoa Trung tâm Tiền Giang

**Trướng Đai hoc Y Dước Cần Tho

Chịu trách nhiệm chính: Lê Hoàng Hạnh

Email: lehoanghanh2707@gmail.com

Ngày nhận bài: 19.01.2021

Ngày phản biên khoa hoc: 18.3.2021

Ngày duyệt bài: 26.3.2021
}

\section{Lê Hoàng Hạnh*, Tạ Văn Trầm*, Lê Thành Tài**, Trần Thị Phương Đan**}

caused by oral disease in the community. Objective: in order to evaluate tooth decay prevention's effectiveness among 12-year-old students in Tien Giang province. Methods: using controlled intervention study, 1259 students who have no tooth decay divided into 3 groups, oral health education intervention, fluoride mouthwash, dental fissure filling for 18 months, and evaluation of outcomes results after 30 months. Results: after the intervention, the percentage of students with tooth decay gradually decreased in the control group, intervention group 1, and intervention group 2 , respectively $48.3 \%, 17.2 \%$ and $10.1 \%$. The intervention efficiency between intervention group 1 and 2 compared with the control group was on average Decayed Missing Filled Teeth (DMFT) and Decayed Missing Filled Surfaces (DMFS) increased $1225 \%-1300 \%$ and $850.6 \%-856.3 \%$. The preventive effect of tooth decay in the intervention group 2 was higher than the intervention group 1. After filling the pit tooth groove with Fuji VII: the percentage of students with tooth decay in the intervention group (1.8\%) was lower than the control group (9.3\%); the intervention efficiency between the intervention group compared to the control group on the mean DMFT and DMFS increased by $583.3 \%$ and $300 \%$ respectively. Conclusion: the effectiveness of tooth decay prevention increased when combining interventions. Preventive measures for 12-year-old students in Tien Giang province have been highly effective.

Keywords: tooth decay, DMFT, DMFS, Tien Giang.

\section{I. ĐĂT VẤN ĐỀ}

Tai Việt Nam, nhiều năm qua, dù ngành y tế đã nỗ lực triển khai nhiều biện pháp mạnh mẽ kết hợp các chương trình dự phòng, can thiệp cộng đồng nhưng tỷ lệ bệnh sâu răng ở Việt Nam còn rất cao, đặc biệt là ở trẻ em và người cao tuổi. Thực trạng đáng báo động hiện nay là khoảng $90 \%$ người dân có vấn đề về răng miệng, chủ yếu là mắc bệnh sâu răng; tỷ lệ trung bình răng sâu mất trám ở trẻ 5-6 tuổi khoảng 50-60\%, đặc biệt ở lứa 12 tuổi đến 80$85 \%$; tỷ lệ sâu răng sửa ở trẻ là $85-90 \%$, gây 
ảnh hưởng xấu đến hệ răng vĩnh viễn sau này $[1],[4],[6]$. Những thực trạng trên đòi hỏi cần thúc đẩy thiết lập những mục tiêu ưu tiên sức khỏe, nhấn mạnh phản ứng của xã hội về vấn đề sức khỏe răng miệng là cần thiết. Điều này phải có những hành động cụ thể cho một loạt các vấn đề về dịch vụ y tế và những ưu tiên cho sức khỏe cộng đồng đặc biệt là ở trẻ em. Nếu dự phòng tốt thì trẻ em có thể giữ được hàm răng tốt suốt đời, giảm được gánh nặng y tế cho gia đình và xã hội.

Do vậy, vấn đề áp dụng các biên pháp dự phòng bệnh răng miệng ở trẻ em; khám định kỳ, phát hiện sớm, điều trị ngay giai đoạn đầu để có thể giữ được hàm răng tốt là những vấn đề ưu tiên hàng đầu. Tuy nhiên, không thể nào mà có thể khám chữa theo nhu cầu của toàn cộng đồng. Chính vì vậy, quan trọng nhất là phải quan tâm đến dự phòng, dự phòng ngay từ lứa tuổi trẻ em. Mục tiêu nghiên cứu: đánh giá hiệu quả dự phòng bệnh sâu răng ở học sinh 12 tuổi tại tỉnh Tiền Giang.

\section{II. ĐỐI TƯƠNG VÀ PHƯƠNG PHÁP NGHIÊN CỨU}

2.1. Đối tượng: học sinh 12 tuổi ở các trường trung học cơ sở taii tỉnh Tiền Giang.

Tiêuu chuẩn chọn mẫu:

- Học sinh không bị sâu răng.

- Nhà trường, phụ huynh và học sinh đồng ý tham gia nghiên cứu.

- Học sinh tham gia đủ các lân điều tra, can thiệp.

Tiêu chuẩn loai trừ:

- Học sinh khổng hợp tác trong quá trình khám răng miệng, can thiệp.

- Học sinh đang bị viêm nhiễm cấp vùng miệng.

2.2. Thời gian và địa điểm nghiên cứu: từ tháng $1 / 2018$ đến tháng $6 / 2020$ tại các trường trung học cơ sở thuộc khu vực thành thị và nông thôn tại tỉnh Tiền Giang.

\subsection{Phương pháp nghiên cứu}

2.3.1. Thiết kế nghiên cứu: nghiên cứu can thiệp có đối chứng

2.3.2. Cỡ mẫu: áp dụng công thức nghiên cứu đối chứng ngẫu nhiên

$n=\frac{\left\{Z_{1-a / 2} \sqrt{2 P^{*}\left(1-P^{*}\right)}+Z_{1-\beta} \sqrt{P_{1}\left(1-P_{1}\right)+P_{2}\left(1-P_{2}\right)}\right\}^{2}}{\left(P_{1}-P_{2}\right)^{2}}$

Trong đó: - n: cõ mẫu nhỏ nhất cho mỗi nhóm can thiệp, nhóm chứng;

- Zx: hệ số tin cậy, $a=0,05 ; Z_{(1-a / 2)=1,96 ;}$

- Độ mạnh của phép kiểm định $\beta=0,1$;

$Z_{(1-\beta)}=1,28$;

- $\mathrm{P}_{1}$ : tỷ lệ sâu răng trước can thiệp, $\mathrm{P}_{1}=0$;

- $P_{2}=0,05$ (kỳ vọng tỷ lệ sâu răng sau can thiệp)
- $\mathrm{P}^{*}=\left(\mathrm{P}_{1}+\mathrm{P}_{2}\right) / 2=0,025$;

Áp dụng công thức tính được, $n=202$. Vì phương pháp chọn mẫu nhiều giai đoạn nên nhân với $D E=2$. Như vây, cõ mẩu lấy tròn là: 410 học sinh cho mỗi nhóm can thiệp và 410 học sinh cho nhóm chứng.

2.3.3. Phương pháp chọn mẫu. Áp dụng phương pháp chọn mẫu nhiều giai đoạn, nghiên cứu chọn được 12 trường từ 24 trường ở nghiên cứu mô tả cắt ngang 2.921 học sinh, chọn được 1.259 học sinh không sâu răng chia thành 3 nhóm (mỗi nhóm 4 trường).

- Nghiên cứu đánh giá hiệu quả dự phòng bệnh sâu răng, chia thành 3 nhóm: (1) Nhóm chứng: 410 học sinh; (2) Nhóm can thiệp 1: 424 học sinh; (3) Nhóm can thiệp 2: 425 học sinh.

- Nghiên cứu đánh giá hiệu quả trám bít hố rãnh bằng Fuji VII, đối tượng là nhóm can thiệp 2 (425 hoc sinh), chia thành 2 nhóm: (1) Nhóm chứng: phân hàm II, III; (2) Nhóm can thiệp: phân hàm I, IV.

2.4. Nội dung can thiệp: can thiệp 18 tháng và đánh giá kết quả sau 30 tháng.

- Nghiên cứu đánh giá hiệu quả dự phòng bệnh sâu răng:

+ Nhóm chứng (410 học sinh): không can thiệp.

+ Nhóm can thiệp 1 (424 học sinh): giáo dục sức khỏe răng miệng cho học sinh, phụ huynh và giáo viên chủ nhiệm; hướng dẫn học sinh thực hành chải răng đúng cách (phương pháp Bass cải tiến).

+ Nhóm can thiệp 2 (425 học sinh): (1) giáo dục sức khỏe răng miệng cho học sinh, phụ huynh và giáo viên chủ nhiệm; hướng dẫn học sinh thực hành chải răng đúng cách (phương pháp Bass cải tiến); (2) súc miệng nước Colgate ${ }^{\circledR}$ Plax chứa Fluor 0,05\%; (3) trám bít hố rãnh bằng Fuji VII phân hàm I và IV.

- Nghiên cứu đánh giá hiệu quả trám bít hố rãnh bằng Fuji VII:

+ Nhóm chứng: không trám bít hố rãnh phân hàm II và III (nữa hàm trái).

+ Nhóm can thiệp: trám bít hố rãnh Fuji VII phân hàm I và IV (nữa hàm phải).

Phương pháp đánh giá hiệu quả can thiệp:

- Sử dụng chỉ số hiệu quả (CSHQ) để đánh giá một số chỉ số (tỷ lệ \%) thay đổi sau can thiệp so với trước can thiệp. CSHQ $(\%)=\left(p_{1-}-\right.$ $\left.\mathrm{p}_{2}\right) / \mathrm{p}_{1} \times 100$, với: $\mathrm{p}_{1}$ : tỷ lệ trước can thiệp), $\mathrm{p}_{2}$ : (tỷ lệ sau can thiệp).

- Sử dụng chỉ số can thiêp (CSCT) (\%) để đánh giá hiệu quả can thiệp giữa nhóm can thiệp (ct) và nhóm đối chứng (đc): CSCT (\%) = CSHQct - CSHQđc. 
2.5. Xử lý và phân tích số liệu: phần mềm SPSS 20.0 .

III. KẾT QUẢ NGHIÊN CỨU

3.1. Hiệu quả dự phòng bệnh sâu răng

Bảng 1. Tỷ lể bểnh sâu răng, mất răng, trám răng trước và sau can thiêp

\begin{tabular}{|c|c|c|c|c|c|c|c|c|c|c|}
\hline \multirow[b]{2}{*}{$\begin{array}{c}n \\
(\%)\end{array}$} & \multicolumn{3}{|c|}{ Chứng } & \multicolumn{3}{|c|}{ Can thiêp 1} & \multicolumn{3}{|c|}{ Can thiêp 2} & \multirow{2}{*}{$\begin{array}{c}\text { CSCT } \\
(6-3) \\
(9-3) \\
(\%)\end{array}$} \\
\hline & $\begin{array}{c}\text { Trức } \\
(1) \\
n=410\end{array}$ & $\begin{array}{c}\text { Sau } \\
(2) \\
n=356\end{array}$ & $\begin{array}{c}\text { CSHQ } \\
(3) \\
(\%)\end{array}$ & $\begin{array}{c}\text { Trưó́c } \\
(4) \\
n=424\end{array}$ & $\begin{array}{c}\text { Sau } \\
(5) \\
n=400\end{array}$ & $\begin{array}{c}\text { CSHQ } \\
(6) \\
(\%)\end{array}$ & $\begin{array}{c}\text { Trước } \\
(7) \\
n=425\end{array}$ & $\begin{array}{c}\text { Sau } \\
(8) \\
n=388\end{array}$ & $\begin{array}{c}\text { CSHQ } \\
(9) \\
(\%)\end{array}$ & \\
\hline \multicolumn{11}{|c|}{ Sâu răng } \\
\hline Có & $\begin{array}{c}0 \\
(0)\end{array}$ & $\begin{array}{c}48,3 \\
(172)\end{array}$ & - & $\begin{array}{c}0 \\
(0)\end{array}$ & $\begin{array}{l}17,2 \\
(69)\end{array}$ & - & $\begin{array}{c}0 \\
(0)\end{array}$ & $\begin{array}{l}10,1 \\
\text { (39) }\end{array}$ & - & - \\
\hline Không & $\begin{array}{c}100 \\
(410)\end{array}$ & $\begin{array}{c}51,7 \\
(184)\end{array}$ & 48,3 & $\begin{array}{c}100 \\
(424)\end{array}$ & $\begin{array}{c}82,8 \\
(331)\end{array}$ & 17,2 & $\begin{array}{c}100 \\
(425)\end{array}$ & $\begin{array}{c}89,9 \\
(349)\end{array}$ & 10,1 & $\begin{array}{l}-31,1 \\
-38,2\end{array}$ \\
\hline$p$ & \multicolumn{2}{|l|}{2} & & \multicolumn{2}{|c|}{ - } & & \multicolumn{2}{|l|}{ 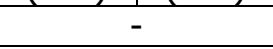 } & \multicolumn{2}{|c|}{$\mathrm{p}_{2-5-8}<0,001^{\mathrm{b}}$} \\
\hline \multicolumn{4}{|c|}{ Mất răng } & & & & & & & \\
\hline Có & $\begin{array}{l}2,0 \\
(8)\end{array}$ & $\begin{array}{c}5,3 \\
(19)\end{array}$ & $-165,0$ & $\begin{array}{l}1,4 \\
(6) \\
\end{array}$ & $\begin{array}{c}2,8 \\
(11) \\
\end{array}$ & $-100,0$ & $\begin{array}{l}1,6 \\
(7)\end{array}$ & $\begin{array}{l}2,3 \\
(9) \\
\end{array}$ & $-43,8$ & $\begin{array}{c}65,0 \\
121,3 \\
\end{array}$ \\
\hline Không & $\begin{array}{c}98,0 \\
(402)\end{array}$ & $\begin{array}{c}94,7 \\
(337)\end{array}$ & 3,4 & $\begin{array}{c}98,6 \\
(418)\end{array}$ & $\begin{array}{c}97,2 \\
(389)\end{array}$ & 1,4 & $\begin{array}{c}98,4 \\
(418)\end{array}$ & $\begin{array}{c}97,7 \\
(379)\end{array}$ & 0,7 & $\begin{array}{l}-2,0 \\
-2,7\end{array}$ \\
\hline$p$ & \multicolumn{2}{|c|}{$\mathrm{p}_{1-2}<0,001^{\mathrm{a}}$} & & \multicolumn{2}{|c|}{$\mathrm{p}_{4-5}=0,031^{\mathrm{a}}$} & & \multicolumn{2}{|c|}{$\mathrm{p}_{7-8}=0,25^{\mathrm{a}}$} & \multicolumn{2}{|c|}{$\mathrm{p}_{2-5-8}=0,051^{\mathrm{b}}$} \\
\hline \multicolumn{4}{|c|}{ Trám răng } & & & & & & & \\
\hline Có & $\begin{array}{c}3,4 \\
(14)\end{array}$ & $\begin{array}{c}5,9 \\
(21)\end{array}$ & $-73,5$ & $\begin{array}{c}3,3 \\
(14)\end{array}$ & $\begin{array}{c}6,8 \\
(27)\end{array}$ & $-106,1$ & $\begin{array}{l}2,1 \\
(9)\end{array}$ & $\begin{array}{c}4,9 \\
(19) \\
\end{array}$ & $-133,3$ & $\begin{array}{l}-32,6 \\
-59,8\end{array}$ \\
\hline Không & $\begin{array}{c}96,6 \\
(396)\end{array}$ & $\begin{array}{c}94,1 \\
(335)\end{array}$ & 2,6 & $\begin{array}{c}96,7 \\
(410)\end{array}$ & $\begin{array}{c}93,2 \\
(373)\end{array}$ & 3,6 & $\begin{array}{c}97,9 \\
(416)\end{array}$ & $\begin{array}{c}95,1 \\
(369)\end{array}$ & 2,9 & $\begin{array}{l}1,0 \\
0,3\end{array}$ \\
\hline$p$ & \multicolumn{2}{|c|}{$\mathrm{p}_{1-2}=0,189^{\mathrm{a}}$} & & \multicolumn{2}{|c|}{$\mathrm{p}_{4-5}=0,029^{\mathrm{a}}$} & & \multicolumn{2}{|c|}{$\mathrm{p}_{7-8}=0,05^{\mathrm{a}}$} & \multicolumn{2}{|c|}{$\mathrm{p}_{2-5-8}=0,54^{\mathrm{b}}$} \\
\hline
\end{tabular}

aMcNemar; ${ }^{b}$ Chi-Square

Bảng 2. Trung binh SMTR, SMTMR trước và sau can thiệp

\begin{tabular}{|c|c|c|c|c|c|c|c|c|c|c|}
\hline \multirow{2}{*}{$\begin{array}{c}\text { Trung } \\
\text { bình } \\
\text { (ĐLC) }\end{array}$} & \multicolumn{3}{|c|}{ Chứng } & \multicolumn{3}{|c|}{ Can thiệp 1} & \multicolumn{3}{|c|}{ Can thiệp 2} & \multirow{2}{*}{$\begin{array}{c}\text { CSCT } \\
(6-3) \\
(9-3) \\
(\%) \\
\end{array}$} \\
\hline & $\begin{array}{c}\begin{array}{c}\text { Trước } \\
(1) \\
n=410\end{array} \\
\end{array}$ & $\begin{array}{c}\text { Sau } \\
(2) \\
n=356\end{array}$ & $\begin{array}{c}\text { CSHQ } \\
(3) \\
(\%) \\
\end{array}$ & $\begin{array}{c}\text { Trước } \\
(4) \\
n=424\end{array}$ & $\begin{array}{c}\text { Sau } \\
(5) \\
n=400\end{array}$ & $\begin{array}{c}\text { CSHQ } \\
(6) \\
(\%)\end{array}$ & $\begin{array}{c}\text { Trước } \\
(7) \\
n=425\end{array}$ & $\begin{array}{c}\text { Sau } \\
(8) \\
n=388\end{array}$ & $\begin{array}{c}\text { CSHQ } \\
(9) \\
(\%)\end{array}$ & \\
\hline \multicolumn{11}{|c|}{ SMTR } \\
\hline \multirow[t]{2}{*}{ âu } & $\begin{array}{c}0 \\
(0) \\
\end{array}$ & $\begin{array}{r}1,10 \\
(1,57 \\
\end{array}$ & - & $\begin{array}{c}0 \\
(0) \\
\end{array}$ & $\begin{array}{c}0,31 \\
(0,82)\end{array}$ & - & $\begin{array}{c}0 \\
(0) \\
\end{array}$ & $\begin{array}{c}0,23 \\
(0,72)\end{array}$ & - & - \\
\hline & \multicolumn{2}{|c|}{$1-2<0,001^{a}$} & & \multicolumn{2}{|c|}{$\mathrm{p}_{4-5}<0,001^{\mathrm{a}}$} & & \multicolumn{2}{|c|}{$\mathrm{p}_{7-8}<0,001^{\mathrm{a}}$} & \multicolumn{2}{|c|}{$\mathrm{p}_{2-5-8}<0,001^{b}$} \\
\hline \multirow[t]{2}{*}{ lất } & $\begin{array}{c}0,02 \\
(0,18)\end{array}$ & $\begin{array}{r}0,07 \\
(0,30 \\
\end{array}$ & $-250,0$ & $\begin{array}{c}0,02 \\
(0,22)\end{array}$ & $\begin{array}{c}0,03 \\
(0,19) \\
\end{array}$ & $-50,0$ & $\begin{array}{c}0,02 \\
(0,13)\end{array}$ & $\begin{array}{c}0,03 \\
(0,17) \\
\end{array}$ & $-50,0$ & $\begin{array}{l}200 \\
200 \\
\end{array}$ \\
\hline & $n-0$ &, $002^{\mathrm{a}}$ & & $\mathrm{p}_{4-5}=$ & $0,02^{a}$ & & $p_{7-8}=0$ & $102^{\mathrm{a}}$ & $\mathrm{p}_{2-5-8}=$ &, $049^{\mathrm{b}}$ \\
\hline \multirow[t]{2}{*}{ Trán } & $\begin{array}{c}0,05 \\
(0,26)\end{array}$ & $\begin{array}{c}0,10 \\
(0,47)\end{array}$ & $-100,0$ & $\begin{array}{c}0,05 \\
(0,31)\end{array}$ & $\begin{array}{c}0,12 \\
(0,51)\end{array}$ & $-140,0$ & $\begin{array}{c}0,04 \\
(0,31)\end{array}$ & $\begin{array}{c}0,09 \\
(0,44)\end{array}$ & $-125,0$ & $\begin{array}{r}-40,0 \\
-25,0 \\
\end{array}$ \\
\hline & \multicolumn{2}{|c|}{$\mathrm{p}_{1-2}=0,058^{\mathrm{a}}$} & & \multicolumn{2}{|c|}{$\mathrm{p}_{4-5}=0,031^{\mathrm{a}}$} & & \multicolumn{2}{|c|}{$\mathrm{p}_{7-8}=0,102^{\mathrm{a}}$} & \multicolumn{2}{|c|}{$\mathrm{p}_{2-5-8}=0,554^{\mathrm{b}}$} \\
\hline \multirow[t]{2}{*}{ SMTP } & $\begin{array}{c}0,07 \\
(0,32)\end{array}$ & $\begin{array}{c}1,26 \\
(1,71)\end{array}$ & 700 & $\begin{array}{c}0,08 \\
(0,43)\end{array}$ & $\begin{array}{c}0,46 \\
(1,05)\end{array}$ & $-475,0$ & $\begin{array}{c}0,07 \\
(0,38)\end{array}$ & $\begin{array}{c}0,35 \\
(0,92) \\
\end{array}$ & $-4 c$ & $\begin{array}{l}1225 \\
1300 \\
\end{array}$ \\
\hline & &, $001^{\mathrm{a}}$ & & \multicolumn{2}{|c|}{$\mathrm{p}_{4-5}<0,001^{\mathrm{a}}$} & & \multicolumn{2}{|c|}{$\mathrm{p}_{7-8}<0,001^{\mathrm{a}}$} & \multicolumn{2}{|c|}{$\mathrm{p}_{2-5-8}<0,001^{b}$} \\
\hline \multicolumn{4}{|c|}{ SMTMR } & & & & & & & \\
\hline \multirow{2}{*}{$\begin{array}{l}\text { Mặt } \\
\text { sâu }\end{array}$} & $\begin{array}{c}0 \\
(0) \\
\end{array}$ & 1,54 & - & $\begin{array}{c}0 \\
(0) \\
\end{array}$ & \begin{tabular}{|c|}
0,35 \\
$(1,01)$ \\
\end{tabular} & - & $\begin{array}{c}0 \\
(0) \\
\end{array}$ & \begin{tabular}{c|}
0,28 \\
$(0,95)$ \\
\end{tabular} & - & - \\
\hline & \multicolumn{2}{|c|}{$\mathrm{p}_{1-2}<0,001^{\mathrm{a}}$} & & \multicolumn{2}{|c|}{$\mathrm{p}_{4-5}<0,001^{\mathrm{a}}$} & & \multicolumn{2}{|c|}{$\mathrm{p}_{7-8}<0,001^{\mathrm{a}}$} & \multicolumn{2}{|c|}{$\mathrm{p}_{2-5-8}<0,001^{\mathrm{b}}$} \\
\hline \multirow[t]{2}{*}{ Mặt mất } & $\begin{array}{c}0,12 \\
(0,92)\end{array}$ & $\begin{array}{c}0,34 \\
(1,51) \\
\end{array}$ & $-183,3$ & $\begin{array}{c}0,12 \\
(1,12)\end{array}$ & $\begin{array}{c}0,15 \\
(0,92)\end{array}$ & $-25,0$ & $\begin{array}{c}0,08 \\
(0,64)\end{array}$ & $\begin{array}{c}0,11 \\
(0,71)\end{array}$ & $-37,5$ & $\begin{array}{l}158,3 \\
145,8 \\
\end{array}$ \\
\hline & \multicolumn{2}{|c|}{$\mathrm{p}_{1-2}=0,002^{\mathrm{a}}$} & & \multicolumn{2}{|c|}{$\mathrm{p}_{4-5}=0,023^{\mathrm{a}}$} & & \multicolumn{2}{|c|}{$p_{7-8}=0,102^{a}$} & \multicolumn{2}{|c|}{$\mathrm{p}_{2-5-8}=0,054^{\mathrm{b}}$} \\
\hline Mặt trám & $\begin{array}{c}0,05 \\
(0,27)\end{array}$ & $\begin{array}{c}0,11 \\
(0,53)\end{array}$ & $-120,0$ & $\begin{array}{c}0,05 \\
(0,30)\end{array}$ & $\begin{array}{c}0,14 \\
(0,62)\end{array}$ & $-180,0$ & $\begin{array}{c}0,04 \\
(0,31)\end{array}$ & $\begin{array}{c}0,11 \\
(0,56)\end{array}$ & $-175,0$ & $\begin{array}{l}-60,0 \\
-55,0\end{array}$ \\
\hline
\end{tabular}


VIETNAM MEDICAL JOURNAL N01 - APRIL - 2021

\begin{tabular}{|c|c|c|c|c|c|c|c|c|c|c|}
\hline & \multicolumn{2}{|c|}{$p_{1-2}=0,042^{a}$} & & \multicolumn{2}{|c|}{$\mathrm{p}_{4-5}=0,01^{\mathrm{a}}$} & & \multicolumn{2}{|c|}{$\mathrm{p}_{7-8}=0,061^{\mathrm{a}}$} & \multicolumn{2}{|c|}{$\mathrm{p}_{2-5-8}=0,561^{\mathrm{b}}$} \\
\hline \multirow[t]{2}{*}{ SMTM } & $\begin{array}{c}0,17 \\
(0,96)\end{array}$ & $\begin{array}{c}1,99 \\
(3,56)\end{array}$ & $-1070,6$ & $\begin{array}{c}0,20 \\
(1,40)\end{array}$ & $\begin{array}{c}0,64 \\
(1,69)\end{array}$ & $-220,0$ & $\begin{array}{c}0,14 \\
(0,80)\end{array}$ & $\begin{array}{c}0,44 \\
(1,25)\end{array}$ & $-214,3$ & $\begin{array}{l}850,6 \\
856,3\end{array}$ \\
\hline & \multicolumn{2}{|c|}{$\mathrm{p}_{1-2}<0,001^{\mathrm{a}}$} & & \multicolumn{2}{|c|}{$\mathrm{p}_{4-5}<0,001^{\mathrm{a}}$} & & \multicolumn{2}{|c|}{$\mathrm{p}_{7-8}<0,001^{\mathrm{a}}$} & \multicolumn{2}{|c|}{$p_{2-5-8}<0,001^{b}$} \\
\hline
\end{tabular}

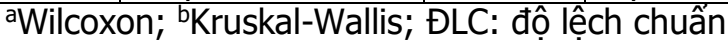

3.2. Hiệu quả dự phòng sâu răng khi trám bít hố rãnh bằng Fuji VII

Bảng 3. Tý lệ bệ̉nh sâu răng, mất răng, trám răng trước và sau can thiệp

\begin{tabular}{|c|c|c|c|c|c|c|c|}
\hline \multirow[b]{2}{*}{$n(\%)$} & \multicolumn{3}{|c|}{ Nhóm chứng } & \multicolumn{3}{|c|}{ Nhóm can thiệp } & \multirow[b]{2}{*}{$\begin{array}{c}\text { CSCT } \\
(\%)\end{array}$} \\
\hline & $\begin{array}{c}\text { Trước(1) } \\
n=425\end{array}$ & $\begin{array}{l}\text { Sau(2) } \\
n=388\end{array}$ & $\begin{array}{c}\text { CSHQ } \\
(\%)\end{array}$ & $\begin{array}{c}\text { Trước(3) } \\
n=425\end{array}$ & $\begin{array}{l}\text { Sau(4) } \\
n=388\end{array}$ & $\begin{array}{c}\text { CSHQ } \\
(\%)\end{array}$ & \\
\hline \multicolumn{8}{|l|}{ Sâu răng } \\
\hline Có & $0(0)$ & $9,3(36)$ & $\begin{array}{l}- \\
-\end{array}$ & $0(0)$ & $1,8(7)$ & $\begin{array}{l}- \\
\end{array}$ & - \\
\hline Không & $100(425)$ & $90,7(352)$ & 9,3 & $100(425)$ & $98,2(381)$ & 1,8 & $-7,5$ \\
\hline $\mathrm{p}$ & \multicolumn{2}{|l|}{-} & & \multicolumn{2}{|c|}{ - } & \multicolumn{2}{|c|}{$\mathrm{p}_{2-4}<0,001^{\mathrm{b}}$} \\
\hline \multicolumn{8}{|l|}{ Mất răng } \\
\hline Có & $1,6(7)$ & $1,8(7)$ & $-12,5$ & $1,6(7)$ & $2,3(9)$ & $-43,8$ & $-31,3$ \\
\hline Không & $98,4(418)$ & $98,2(381)$ & 0,2 & $98,4(418)$ & $97,7(379)$ & 0,7 & 0,5 \\
\hline$p$ & \multicolumn{2}{|c|}{$\mathrm{p}_{1-2}=1^{\mathrm{a}}$} & & \multicolumn{2}{|c|}{$\mathrm{p}_{3-4}=0,25^{\mathrm{a}}$} & \multicolumn{2}{|c|}{$\mathrm{p}_{2-4}=0,613^{\mathrm{b}}$} \\
\hline \multicolumn{8}{|l|}{ Trám răng } \\
\hline Có & $2,1(9)$ & $5,2(20)$ & $-147,6$ & $2,1(9)$ & $5,2(20)$ & $-147,6$ & 0 \\
\hline Không & $97,9(416)$ & $94,8(368)$ & 3,2 & $97,9(416)$ & $94,8(368)$ & 3,2 & 0 \\
\hline $\mathrm{p}$ & \multicolumn{2}{|c|}{$\mathrm{p}_{1-2}=0,001^{\mathrm{a}}$} & & \multicolumn{2}{|c|}{$\mathrm{p}_{3-4}=0,001^{\mathrm{a}}$} & \multicolumn{2}{|c|}{$\mathrm{p}_{2-4}=1^{\mathrm{b}}$} \\
\hline
\end{tabular}

${ }^{a}$ McNemar; ${ }^{b}$ Chi-Square

Bảng 4. Trung binh SMTR, SMTMR trước và sau can thiệp

\begin{tabular}{|c|c|c|c|c|c|c|c|}
\hline \multirow{2}{*}{$\begin{array}{l}\text { Trung } \\
\text { bình } \\
\text { (ĐLC) }\end{array}$} & \multicolumn{3}{|c|}{ Nhóm chứng } & \multicolumn{3}{|c|}{ Nhóm can thiệp } & \multirow[b]{2}{*}{$\begin{array}{c}\text { CSCT } \\
(\%)\end{array}$} \\
\hline & $\begin{array}{c}\text { Trước(1) } \\
n=425\end{array}$ & $\begin{array}{l}\text { Sau(2) } \\
n=388\end{array}$ & $\begin{array}{c}\text { CSHQ } \\
(\%)\end{array}$ & $\begin{array}{c}\text { Trước(3) } \\
n=425\end{array}$ & $\begin{array}{l}\text { Sau(4) } \\
n=388\end{array}$ & $\begin{array}{c}\text { CSHQ } \\
(\%)\end{array}$ & \\
\hline \multicolumn{8}{|c|}{ SMTR } \\
\hline \multirow{2}{*}{ Sâu } & $0(0)$ & $0,20(0,65)$ & - & $0(0)$ & $0,04(0,29)$ & - & - \\
\hline & \multicolumn{2}{|c|}{$\mathrm{p}_{1-2}<0,001^{\mathrm{a}}$} & & \multicolumn{2}{|c|}{$p_{3-4}=0,011^{\mathrm{a}}$} & \multicolumn{2}{|c|}{$\mathrm{p}_{2-4}<0,001^{\mathrm{b}}$} \\
\hline \multirow{2}{*}{ Mất } & $0,01(0,06)$ & $0,02(0,13)$ & $-100,0$ & $0,01(0,06)$ & $0,02(0,15)$ & $-100,0$ & 0 \\
\hline & \multicolumn{2}{|c|}{$p_{1-2}=0,011^{a}$} & & \multicolumn{2}{|c|}{$\mathrm{p}_{3-4}=0,006^{\mathrm{a}}$} & \multicolumn{2}{|c|}{$\mathrm{p}_{2-4}=0,614^{\mathrm{b}}$} \\
\hline \multirow{2}{*}{ Trám } & $0,02(0,15)$ & $0,07(0,30)$ & $-250,0$ & $0,02(0,15)$ & $0,05(0,24)$ & $-150,0$ & 100 \\
\hline & \multicolumn{2}{|c|}{$\mathrm{p}_{1-2}=0,001^{\mathrm{a}}$} & & \multicolumn{2}{|c|}{$\mathrm{p}_{3-4}=0,002^{\mathrm{a}}$} & \multicolumn{2}{|c|}{$\mathrm{p}_{2-4}=0,853^{\mathrm{b}}$} \\
\hline \multirow{2}{*}{ SMTR } & $0,03(0,17)$ & $0,28(0,77)$ & $-883,3$ & $0,03(0,17)$ & $0,12(0,41)$ & $-300,0$ & 583,3 \\
\hline & \multicolumn{2}{|c|}{$\mathrm{p}_{1-2}<0,001^{\mathrm{a}}$} & & \multicolumn{2}{|c|}{$\mathrm{p}_{3-4}<0,001^{\mathrm{a}}$} & \multicolumn{2}{|c|}{$\mathrm{p}_{2-4}=0,004^{\mathrm{b}}$} \\
\hline \multicolumn{8}{|c|}{ SMTMR } \\
\hline \multirow{2}{*}{ Mặt sâu } & $0(0)$ & $0,24(0,87)$ & - & $0(0)$ & $0,12(0,68)$ & - & \\
\hline & \multicolumn{2}{|c|}{$\mathrm{p}_{1-2}<0,001^{\mathrm{a}}$} & & \multicolumn{2}{|c|}{$\mathrm{p}_{3-4}=0,001^{\mathrm{a}}$} & \multicolumn{2}{|c|}{$\mathrm{p}_{2-4}=0,001^{\mathrm{b}}$} \\
\hline \multirow{2}{*}{ Mặt mất } & $0,02(0,15)$ & $0,09(0,67)$ & $-350,0$ & $0,02(0,15)$ & $0,04(0,44)$ & $-100,0$ & 250,0 \\
\hline & \multicolumn{2}{|c|}{$\mathrm{p}_{1-2}=0,169^{\mathrm{a}}$} & & \multicolumn{2}{|c|}{$p_{3-4}=0,975^{a}$} & \multicolumn{2}{|c|}{$p_{2-4}=0,554^{b}$} \\
\hline \multirow{2}{*}{ Mặt trám } & $0,04(0,32)$ & $0,07(0,31)$ & $-75,0$ & $0,04(0,32)$ & $0,07(0,44)$ & $-75,0$ & 0 \\
\hline & \multicolumn{2}{|c|}{$\mathrm{p}_{1-2}=0,255^{\mathrm{a}}$} & & \multicolumn{2}{|c|}{$\mathrm{p}_{3-4}=0,255^{\mathrm{a}}$} & \multicolumn{2}{|c|}{$\mathrm{p}_{2-4}=1^{\mathrm{b}}$} \\
\hline \multirow{2}{*}{ SMTMR } & $0,06(0,36)$ & $0,4(1,2)$ & $-566,7$ & $0,06(0,36)$ & $0,22(0,86)$ & $-266,7$ & 300 \\
\hline & $p_{1-2}$ & $001^{a}$ & & $\mathrm{p}_{3-4}$ & $001^{a}$ & $\mathrm{p}_{2-4}=$ & $007^{b}$ \\
\hline
\end{tabular}

aWilcoxon; 'Mann-Whitney; ĐLC: độ lệch chuẩn

\section{BÀN LUẬN}

4.1. Hiệu quả dự phòng bệnh sâu răng

Sâu răng: sau can thiệp, tỷ lệ học sinh mắc sâu răng giảm dần ở 3 nhóm cụ thể là: tỷ lệ sâu răng cao nhất ở nhóm chứng $(48,3 \%)$, giảm dần ở nhóm can thiệp $1(17,2 \%)$ và thấp nhất ở nhóm can thiệp 2 (10,1\%); sự khác biệt này có ý nghĩa thống kê với $p<0,001$. Trong khi đó, tỷ lệ không sâu răng ở nhóm chứng còn $51,7 \%$ (so với ban đầu là $100 \%$ không sâu răng), chỉ số hiệu quả tăng 48,3\%; nhóm can thiệp 1 tỷ lệ này là $82,3 \%$ với chỉ số hiệu quả tăng $17,2 \%$ và nhóm can thiệp 2 là 89,9\% với chỉ số hiệu quả tăng 10,1\%. Như vậy, chỉ số can thiệp (hiệu quả can thiệp) 
giữa nhóm can thiệp 1 và nhóm chứng trên tỷ lệ không sâu răng giảm 31,1\%; giữa nhóm can thiệp 2 và nhóm chứng giảm $38,2 \%$.

Mât răng: tỷ lệ mất răng ở nhóm chứng tăng từ $2 \%$ lên $5,3 \%$ với chỉ số hiệu quả giảm $165,0 \%$; ở nhóm can thiệp 1 tăng từ 1,4\% lên $2,8 \%$ với chỉ số hiệu quả giảm $100,0 \%$ và nhóm can thiệp 2 tăng từ $1,6 \%$ lên $2,3 \%$ với chỉ số hiệu quả giảm 43,8\%. Như vậy, hiệu quả can thiêp giữa nhóm can thiệp 1 và nhóm chứng trên tỷ lệ mất răng tăng 65\%; giữa nhóm can thiệp 2 và nhóm chứng tăng $121,3 \%$.

Trám răng: tỷ lệ trám răng ở nhóm chứng tăng từ 3,4\% lên $5,9 \%$ với chỉ số hiệu quả giảm $73,5 \%$; ở nhóm can thiệp 1 tăng từ 3,3\% lên $6,8 \%$ với chỉ số hiệu quả giảm $106,1 \%$ và ở nhóm can thiệp 2 tăng từ $2,1 \%$ lên $4,9 \%$ với chỉ số hiệu quả giảm $133,3 \%$. Như vâyy, chỉ số can thiệp giữa nhóm can thiệp 1 và nhóm chứng trên tỷ lệ trám răng giảm $32,6 \%$; giữa nhóm can thiệp 2 và nhóm chứng giảm $59,8 \%$.

Nghiên cứu của Nguyễn Anh Sơn (2019) thực hiện tại Vĩnh Phúc cũng ghi nhận tỷ lệ học sinh bị sâu răng sau can thiệp giảm so với trước can thiệp ở nhóm can thiệp và so với nhóm chứng là $20,61 \%$, sự khác biệt này có ý nghĩa thống kê $(p<0,05)$ [4]. Trần Tấn Tài $(2016)$ thực hiện nghiên cứu tương tự tài Thừa Thiên Huế cho thây tỷ lệ sâu răng mới trong nhóm can thiệp là $25,7 \%$, trong khi nhóm đối chứng là $56,6 \%$, sự khác biệt có ý nghĩa thống kê với $p<0,01$ [5]. Tạ Quốc Đại (2012), nghiên cứu đánh giá hiệu quả kiểm soát mảng bám răng trong dự phòng sâu răng, viêm nướu ở học sinh 12 tuổi tại một số trường ở ngoại thành Hà Nội đã cho thấy tình trạng vệ sinh răng miệng nhóm can thiệp được cải thiên tốt hơn từ $43,8 \%$ lên $89,7 \%$. Sau can thiệp tỷ lệ sâu răng của nhóm can thiệp $(31,5 \%)$ thấp hơn so với nhóm chứng $(39,3 \%)$, sự khác biệt có ý nghĩa thống kê $(p<0,05)$, như vậy sau can thiệp đã làm kiềm chế sâu răng tăng theo tuổi ở nhóm can thiệp [2].

SMTR: trung bình SMTR ở nhóm chứng tăng từ 0,07 lên 1,26 răng với chỉ số hiệu quả giảm $1700 \%$; ở nhóm can thiệp 1 tăng từ 0,08 lên 0,46 răng với chỉ số hiệu quả giảm $475 \%$ và ở nhóm can thiệp 2 tăng từ 0,07 lên 0,35 răng với chỉ số hiệu quả giảm $400 \%$; sự khác biệt này có ý nghĩa thống kê với $p<0,001$. Như vậy, hiệu quả can thiệp giữa nhóm can thiệp 1 và nhóm chứng trên trung bình SMTR tăng 1225\%; giữa nhóm can thiệp 2 và nhóm chứng tăng $1300 \%$.

SMTMR: trung bình SMTMR ở nhóm chứng tăng từ 0,17 lên 1,99 răng với chỉ số hiệu quả giảm 1070,6\%; ở nhóm can thiệp 1 tăng từ 0,20 lên 0,64 răng với chỉ số hiệu quả giảm $220 \%$ và ở nhóm can thiệp 2 tăng từ 0,14 lên 0,44 răng với chỉ số hiệu quả giảm 214,3\%; sự khác biệt này có ý nghĩa thống kê với $p<0,001$. Như vậy, hiệu quả can thiệp giữa nhóm can thiệp 1 và nhóm chứng trên trung bình SMTMR tăng $850,6 \%$; giữa nhóm can thiệp 2 và nhóm chứng tăng $856,3 \%$.

Nghiên cứu của Vũ Mạnh Tuấn (2013) ghi nhận: sau can thiệp Gel fluor 1,23\%, chỉ số SMTR ở nhóm can thiệp $(1,08)$ tương đương với nhóm chứng $(1,10)$. Gel có tác dụng tái khoáng hóa, ngăn chặn và vô hiệu hóa các tổn thương sâu răng giai đoạn sớm D1, D2 ở răng vĩnh viễn: làm giảm $78,6 \%$ sâu răng vĩnh viễn giai đoạn sớm (D1, D2) sau 18 tháng; nhóm chứng có giảm $11,1 \%$ sâu răng vĩnh viễn giai đoạn sớm (D1, D2). Gel fluor 1,23\% làm giảm chỉ số SMTR trung bình là 2,03 răng và giảm chỉ số SMTMR là 2,63 mặt răng sau 18 tháng [8]. Nghiên cứu của Trần Thị Kim Thúy (2019) đánh giá hiệu quả của nước xúc miêng fluor $0,05 \%$ trên tổn thương sâu răng vĩnh viễn giai đoạn sớm: nước xúc miệng fluor $0,05 \%$ có tác dụng tốt trong tái khoáng hóa, ngăn chặn và vô hiệu hóa các tổn thương sâu răng giai đoạn sớm D1, D2 ở răng vĩnh viễn [6].

4.2. Hiệu quả dự phòng sâu răng khi trám bít hố rãnh bằng Fuji VII. Sau can thiệp, tỷ lệ học sinh mắc sâu răng ở nhóm can thiệp $(1,8 \%)$ thấp hơn có ý nghĩa thống kê so với nhóm chứng $(9,3 \%)$ với $\mathrm{p}<0,001$. Trong khi đó, tỷ lệ không sâu răng ở nhóm chứng còn $90,7 \%$ (so với ban đầu là $100 \%$ không sâu răng), chỉ số hiệu quả tăng 9,3\%; nhóm can thiệp tỷ lệ này là $98,2 \%$ với chỉ số hiệu quả tăng $1,8 \%$. Hiệu quả can thiệp giữa nhóm can thiệp và nhóm chứng trên tỷ lệ không sâu răng giảm $7,5 \%$. Về tỷ lệ mất răng và trám răng: không ghi nhận sự khác biệt có ý nghĩa thống kê giữa 2 nhóm. Ngoài ra, kết quả nghiên cứu ghi nhận trung bình SMTR ở nhóm chứng tăng từ 0,03 lển 0,28 răng với chỉ số hiệu quả giảm $883,3 \%$; ơ nhóm can thiệp tăng từ 0,03 lên 0,12 răng với chỉ số hiệu quả giảm 300\%; như vậy, hiệu quả can thiệp giữa nhóm can thiệp và nhóm chứng trên trung bình SMTR tăng 583,3\%. Bên cạnh đó, trung bình SMTMR ở nhóm chứng tăng từ 0,06 lên 0,4 răng với chỉ số hiệu quả giảm $566,7 \%$; ở nhóm can thiệp tăng từ 0,06 lên 0,22 răng với chỉ số hiệu quả giảm 266,7\%; như vậy, hiệu quả can thiệp giữa nhóm can thiệp và nhóm chứng trên trung bình SMTMR tăng 300\%. 
Phùng Thi Thu Hà (2013), khi đánh giá hiệu quả lâm sàng của Fuji VII trong trám bít hố rãnh dự phòng sâu răng trên các răng hàm lớn thứ nhất ở trẻ em từ 6 đến 9 tuổi cũng ghi nhân: tỷ lệ miếng trám còn nguyên vẹn là $25 / 30$ và $20 / 30$ tương đương $83 \%$ (6 tháng) và $66,7 \%$ (12 tháng). Sau 6 tháng, 100\% các răng được trám bít hố rãnh không xuất hiện sâu răng, độ khít sát hoàn hảo, không bị nứt gãy miếng trám, không thay đổi màu sắc miếng trám. Sau 12 tháng, tỷ lệ xuất hiện sâu răng là $0 \%$, độ khít sát đạt $96,7 \%$ các răng, không nứt gãy miếng trám đạt ở $93,3 \%$ và không thay đổi màu sắc bờ miếng trám là 93,3\% [3]. Tỷ lệ thành công của miếng trám sau 3 và 6 tháng của vật liệu Glassinomer cement là rất cao lần lướt là $86 \%$ và $78 \%$. Điều đó nói lên sâu răng khồng hề xuất hiện ở mặt nhai trong thời gian miếng trám còn nguyên. Mặc dù, chúng ta dự phòng sâu răng theo nhiều hướng khác nhau, nhưng khó có phương pháp dư phòng nào mà lại đạt hiệu quả cao như trám bít hố rãnh [7].

\section{KẾT LUẬN}

Sau can thiệp, tỷ lệ học sinh mắc bệnh sâu răng giảm dần ở nhóm chứng, nhóm can thiệp 1 và nhóm can thiệp 2 lần lượt là 48,3\%; 17,2\% và $10,1 \%$ (có ý nghĩa thống kê với $p<0,001$ ). Hiệu quả can thiệp giữa nhóm can thiệp 1 và 2 so nhóm chứng trên trung bình SMTR và SMTMR tăng lần lượt là $1225 \%-1300 \%$ và $850,6 \%$ $856,3 \%$ (có ý nghĩa thống kê với $p<0,001$ ). Hiệu quả dự phòng bệnh sâu răng ở nhóm can thiệp 2 cao hơn nhóm can thiêp 1. Sau khi trám bít hố rãnh bằng Fuji VII: tỷ lệ học sinh mắc bệnh sâu răng ở nhóm can thiệp $(1,8 \%)$ thấp hớn có ý nghĩa thống kê so với nhóm chứng $(9,3 \%)$ với $p<0,001$; hiệu quả can thiệp giữa nhóm can thiệp so nhóm chứng trên trung bình SMTR và SMTMR tăng lần lượt là $583,3 \%$ và $300 \%$ (có ý nghĩa thống kê với $p<0,05$ ).

\section{TÀI LIÊU THAM KHẢO}

1. Đào Thi Dung (2007), Đánh giá hiệu quả can thiêp chương trinh Nha học đường tại môt số trường tiểu học Quận Đống Đa-Hà Nội, Luận án Tiến sỹ Y học, Trướng Đại học Y Hà Nội.

2. Ta Quốc Điai (2012), Đánh giá hiếu quả kiểm soát mảng bám răng trong dự phòng sâu răng, viêm lợi ớ học sinh 12 tuối tại một số trường ớ ngoại thành Hà Nội, Luận án Tiến sỹ Y học, Viện Về sinh Dịch tễ Trung ưởing.

3. Phùng Thi Thu Hà, Lương Thi Thu Hằng (2013), "Đánh giá hiệu quả lâm sàng của Fuji VII trong trám bít hố rãnh dự phòng sâu răng trên các răng hàm lớn thứ nhất ở trẻ em từ 6 đến 9 tuổi", Y hoc thức hành, 876(7), pp. 88-89.

4. Nguyễn Anh Sơn (2019), Thức trang và một số yểu tố liên quan đến bệnh sâu răng, viêm lợi, hiệu quả can thiệp ở học sinh khối lớp 6 một số trướng trung học cở sở huyện Bình Xuyên, tỉnh Vĩnh Phúc, Lưận án Tiến sỹ Y tể công cộng, Viện Vệ sinh Dịch tế Trung ương.

5. Trân Tấn Tài (2016), Thực trạng bệnh sâu răng và hiêuu quả của giải pháp can thiệp công đồng của hoc sinh tại một số trường tiểu học ở Thừa Thiên Huế, Luân án Tiến sỹ $Y$ hoc, Trường Đai hoc $Y$ Dược Huế.

6. Trần Thị Kim Thúy (2019), Ngghiên cứu dự phòng sâu răng vĩnh viến giai đoạn sớm bằng nước xúc miêng Fluor cho hoc sinh $7-8$ tuổi ở tỉnh Phú Thọ, Luận án Tiến sỹ் Y học, Viện Nghiên cứu Khoa học Y Dược Lâm sàng 108.

7. Trân Đình Tuyên (2012), "Phân tích hiệu quả trám bít hố rãnh trong phòng bệnh sâu răng bằng Glassionomer cement ở trẻ em dưới 15 tuôi qua các nghiên cứu lâm sàng", $Y$ học thực hành, 834(7), pp. 21-22.

8. Vũ Mạnh Tuấn (2013), Nghiên cứu dự phòng sâu răng bằng Gel Fluor, Luận án Tiến sĩ y học, Trường Đại học Y Hà Nội.

\section{ĐẶC ĐIỂM LÂM SÀNG, CÂN LÂM SÀNG CỦA BỆNH NHÂN NGộ ĐộC CẨP Có TOAN LACTIC}

TÓM TẮT

\footnotetext{
${ }^{1}$ Trung tâm Chông độc, Bệnh viện Bạch Mai, 2Bệnh viện Lão khoa Trung ương Chiu trách nhiệm chính: Đăng Thị Xuân Email: xuandangthi@bachmai.edu.vn Ngày nhâan bài: 14.01.2021 Ngày phản biên khoa học: 18.3.2021 Ngày duyệt bài: 26.3.2021
}

Đặng Thị Xuân ${ }^{1}$, Nguyễn Trung Anh ${ }^{2}$

Mục tiêu: mô tả đặc điểm lâm sàng, cận lâm sàng của bệnh nhân ngộ độc cấp có toan lactic. Đối tượng và phướng pháp: nghiên cứu mô tả tiến cứu trên 127 bệnh nhân ngộ độc cấp có toan lactic điều trị tại trung tầm chống độc bệnh viện Bạch Mai từ tháng 07/2019 đến tháng 07/2020. Kết quả: tuổi trung bình của đối tượng nghiên cứu là $37,2 \pm 15,8$. Tỉ lệ nam/ nữ là $1,7 / 1$. Triệu chứng lâm sàng thường gặp là buồn nôn và nôn $(61,4 \%)$, mạch nhanh $(43,3 \%)$, đau đâu $(33,8 \%)$, rối loạn ý thức $(32,2 \%)$, tụt huyết áp $(25,9 \%)$, suy hô hấp $(27,5 \%)$. Xét nghiệm cận lâm sàng biểu thị tình trạng thiếu máu $(34,6 \%)$, tăng bạch 